\title{
EL FONDO DEL MARQUESADO DE LEGARDA EN EL ARCHIVO HISTÓRICO DE LA NOBLEZA (TOLEDO)
}

\section{THE ARCHIVES OF THE MARQUISES OF LEGARDA AT THE ARCHIVO HISTÓRICO DE LA NOBLEZA (TOLEDO)}

\author{
EFRÉN DE LA PEÑA BARROSO \\ Cuerpo Facultativo de Archiveros, Bibliotecarios y Arqueólogos \\ JOSÉ FRANCISCO GUELFI CAMPOS \\ Universidade de São Paulo (Brasil)
}

\begin{abstract}
Resumen: El presente artículo es el resultado de los trabajos realizados sobre el fondo del Marquesado de Legarda, conservado en el Archivo Histórico de la Nobleza, desarrollados en el marco del "Programa de Formación de Profesionales Iberoamericanos en el sector cultural", a finales del año 2012. El trabajo se centró en la identificación somera y descripción pieza a pieza del fondo, que unido al estudio de la organización del archivo seguido durante los siglos XVI a XIX ha dado como resultado el análisis integral de este pequeño fondo. Así, pretendemos dar a conocer las conclusiones históricas y archivísticas en relación a dicho fondo, ofreciendo a la comunidad investigadora un completo panorama en el que se ha reflejado la genealogía de los titulares del marquesado desde su primera generación hasta la actualidad; la organización del archivo durante el Antiguo Régimen; la ordenación física original de los documentos, su descripción y su conservación; y el contenido de la documentación y la utilidad de su información para los estudios históricos. De temática variada, el archivo presenta numerosos documentos relativos a la administración de bienes, al ejercicio de la jurisdicción señorial y a la gestión de las obras pías. Al recorrer sus documentos incluso es posible encontrar fuentes que proporcionan al investigador noticias de algunos episodios de la vida cotidiana. Más que agotar el potencial informativo de dicho archivo, nuestra intención ha sido la de motivar a estudiosos e investigadores a conocer los documentos que lo componen sabiendo que, en cualquier caso, permitirán otras posibilidades de estudio de más amplio alcance.
\end{abstract}




\title{
EFrén de la PeÑa Barroso y José Francisco Guelfi Campos \\ El FONDO DEL MARQUESADO DE LEGARDA EN EL ARCHIVO HistóRICO DE LA NoBLEZA (TOLEDO)
}

Palabras-clave: Archivos nobiliarios, marquesado de Legarda, descripción archivística.

\begin{abstract}
This paper results from an experience with the archives of the marquises of Legarda, held by the Archivo Histórico de la Nobleza, and developed in the context of the "Programa de Formación de Profesionales Iberoamericanos en el sector cultural", between October and December 2012. The work consisted of a summarized identification and archival description, which added to the study of the original archival organization performed between the $16^{\text {th }}$ and the $19^{\text {th }}$ centuries, led to the integral analysis of this fonds. Thus, we aim to shed light to both historical and archival conclusions about such archives, offering a complete outlook on Legarda's genealogy from its first to its current generation; on the archival organization during the Ancien Régime in its external features, original order, archival description, and conservation; and on the archives' content and informational potential. The archives contains plenty of documents on diverse themes, as property management, master's jurisdiction exercise, and charity affairs. While examining the documents, it is also possible to find sources on episodes of everyday life and criminal cases. More than exhaust the archives' informational potential, we hope to foster scholars and researchers to know the documents left by the marquises of Legarda, taking into account that in any case they will allow new possibilities for deeper studies.
\end{abstract}

Keywords: Nobility archives, marquises of Legarda, archival description.

\section{INTRODUCCIÓN.}

En estos últimos años, la Subdirección General de los Archivos Estatales del Ministerio de Educación, Cultura y Deporte ha desarrollado distintos programas de cooperación cultural con las instituciones archivísticas de numerosos países iberoamericanos.

Uno de ellos es el "Programa de Formación de Profesionales Iberoamericanos en el sector cultural", dentro del cual se insertan las denominadas Estancias. Por ellas, los archivos dependientes de dicho Ministerio reciben anualmente la visita de archiveros de esa procedencia durante un plazo aproximado de dos meses.

En el marco de estas Estancias, enriquecedora fuente de intercambio de experiencias y conocimientos de las tradiciones y procedimientos de trabajo de los países de origen y de destino, y concretamente de la Estancia 29-E ("Estancia de 


\section{EFrÉn de la PEÑA BARroso y José Francisco Guelfi CAMPOS \\ El FONDO DEL MARQUESAdo DE LEGARDA EN EL ARCHIVO HistóRICO DE LA NoblezA (Toledo)}

gestión de fondos documentales privados"), el Archivo Histórico de la Nobleza de Toledo tuvo la fortuna de acoger a finales del año 2012 a dos jóvenes pero experimentados archiveros procedentes de Venezuela y de Brasil. El trabajo que desarrollaron en el centro fue el de la identificación somera y la descripción del fondo de los marqueses de Legarda, que unido al estudio de la organización del archivo seguidos durante los siglos XVI a XIX han dado como resultado el análisis integral de este pequeño fondo.

Con este artículo, los autores pretendemos dar a conocer las conclusiones históricas y archivísticas de la mencionada Estancia en relación con el fondo Legarda conservado en el Archivo Histórico de la Nobleza de Toledo, ofreciendo a la comunidad investigadora un completo panorama en el que se atenderá a la genealogía de los titulares del marquesado, a la organización del archivo de la Casa durante el Antiguo Régimen y al contenido de la documentación y la utilidad de su información ${ }^{1}$.

\section{GENEALOGÍA DEL MARQUESADO.}

Antes de comenzar este epígrafe, es necesario advertir que todavía no se ha realizado ningún estudio en profundidad sobre la historia institucional del marquesado de Legarda, tal vez porque los fondos más antiguos de su archivo no alcanzan más alla de la mitad del siglo XVI. Sin embargo, y a falta de documentación que permita estudiar los orígenes del título nobiliario, sí es posible trazar una somera historia genealógica de los últimos señores de Legarda hasta que les fue concedido el título de marqueses a mediados del siglo XVII.

En su origen, el título de Legarda estuvo vinculado al linaje de Salcedo. Más tarde pasó al de Peralta-Cárdenas y después al de Esquivel, y actualmente se encuentra vinculado a la familia Fernández de Navarrete. El linaje de Salcedo tenía su solar en la villa de Valmaseda (Vizcaya), en la comarca de las Encartaciones, donde sus miembros habían vivido desde antiguo. Parece que un miembro de la familia, doña Mencía Ortíz de Salcedo y Zúñiga, contrajo matrimonio a comienzos del siglo XV con Hurtado Díaz de Mendoza, señor de Legarda, unión que vinculó definitivamente el linaje de Salcedo con los señores de Legarda. Su heredero Lope Hurtado de Salcedo, señor de Legarda, decidió entonces descender de

${ }^{1}$ El autor Efrén de la Peña Barroso ha sido Jefe de Organización de Fondos y Normalización del Archivo Histórico de la Nobleza hasta el mes de abril del año 2014. 


\section{EFrÉn de la Peña Barroso y José Francisco Guelfi Campos \\ El FONDO DEL MARQUESADO DE LEGARDA EN El ARCHIVO HistóRICO DE LA NoBLEZA (Toledo)}

las montañas y establecerse en la villa alavesa que daba nombre a su señorío, plaza que se había configurado como un importante nudo de caminos entre el Valle del Ebro y Bilbao ${ }^{2}$.

Los árboles genealógicos que hemos encontrado no se remontan más atrás del siglo XVI ${ }^{3}$. El primer dato con rigor histórico que conocemos es que Diego de Urrutia, señor de la Casa y Torre de Valmaseda, casó con Catalina Hurtado de Salcedo, hermana del señor de Legarda, en algún momento en el tránsito al siglo XVI. De este matrimonio nació Juan de Urrutia Mendoza y Salcedo, que también fue señor de la Casa y Torre de Valmaseda pero que todavía no aparece intitulado como señor de Legarda. Esto quizá se debiese a que por entonces el señorío de Legarda lo ostentaba Diego Hurtado de Salcedo, según se recoge en la documentación ${ }^{4}$, aunque este personaje no ha podido ser encajado en nuestra genealogía por falta de datos sobre su parentesco.

De la unión entre Juan de Urrutia y María Sáez (o Sanz) de los Llanos nació Juan Hurtado de Salcedo y Sáez de los Llanos, que ya figura como señor de Legarda y también de las Casas de Salcedo y Urrutia, caballero de la Orden de Alcántara y corregidor de la ciudad de Ávila. Juan Hurtado casó con Casilda de Velasco y Hierro, y juntos tuvieron a Francisco Hurtado de Salcedo y Ortíz de Velasco (1594-1649), señor de Salcedo y Legarda y padre del I marqués de Legarda.

Árbol genealógico de los señores de Legarda hasta el I marqués de Legarda:

${ }^{2}$ En G. B. TARRAGÓ, “De 'Las Montañas' al Río de la Plata: gobernadores cántabros en Buenos Aires (primera mitad del siglo XVIII)", en Monte Buciero 12, (2006), p. 105. No hemos localizado documentación de archivo que confirme estos datos. Recurso electrónico: http://dialnet. unirioja.es/servlet/articulo? codigo $=2230643$

${ }^{3}$ Exiten tres árboles genealógicos de esta fecha que hemos consultado a través de la Biblioteca Digital de la Real Academia de la Historia: RAH, Salazar y Castro, signatura 9/296, fol. 263r, olim D.21, fol. 263: "costados de Antonio Hurtado de Salcedo, de Urrutia y Serralta, Velasco y de Hoyo, I marqués de Legarda, señor de las casas de Salcedo y de Urruti". Sin fecha; signatura 9/294, fol. 285r, olim D.19, fol. 285: "costados de doña Bernarda Hurtado de Salcedo y Coterillo, Serralta y Ortega, II marquesa de Legarda". Fechado en 1683; signatura 9/295, fol. 107r, olim D.20, fol. 107: “costados de Juan José de Peralta y Hurtado de Mendoza, Ocampo y Coterilla, III marqués de Legarda”. Sin fecha.

${ }^{4}$ Sabemos que Diego Hurtado de Salcedo, señor de Legarda, tuvo que dar una carta de seguro a favor de Juan de Murna, quien se temía de dicho señor por ciertas acusaciones que el último había vertido contra él. En Archivo General de Simancas (en adelante, AGS), Registro General del Sello (en adelante, RGS), 150906, 543. Fechado el 7 de junio de 1509. Unos meses después se probó la inocencia de Juan de Murna. En AGS, RGS, 151001, 392. Fechado el 26 de enero de 1510. 

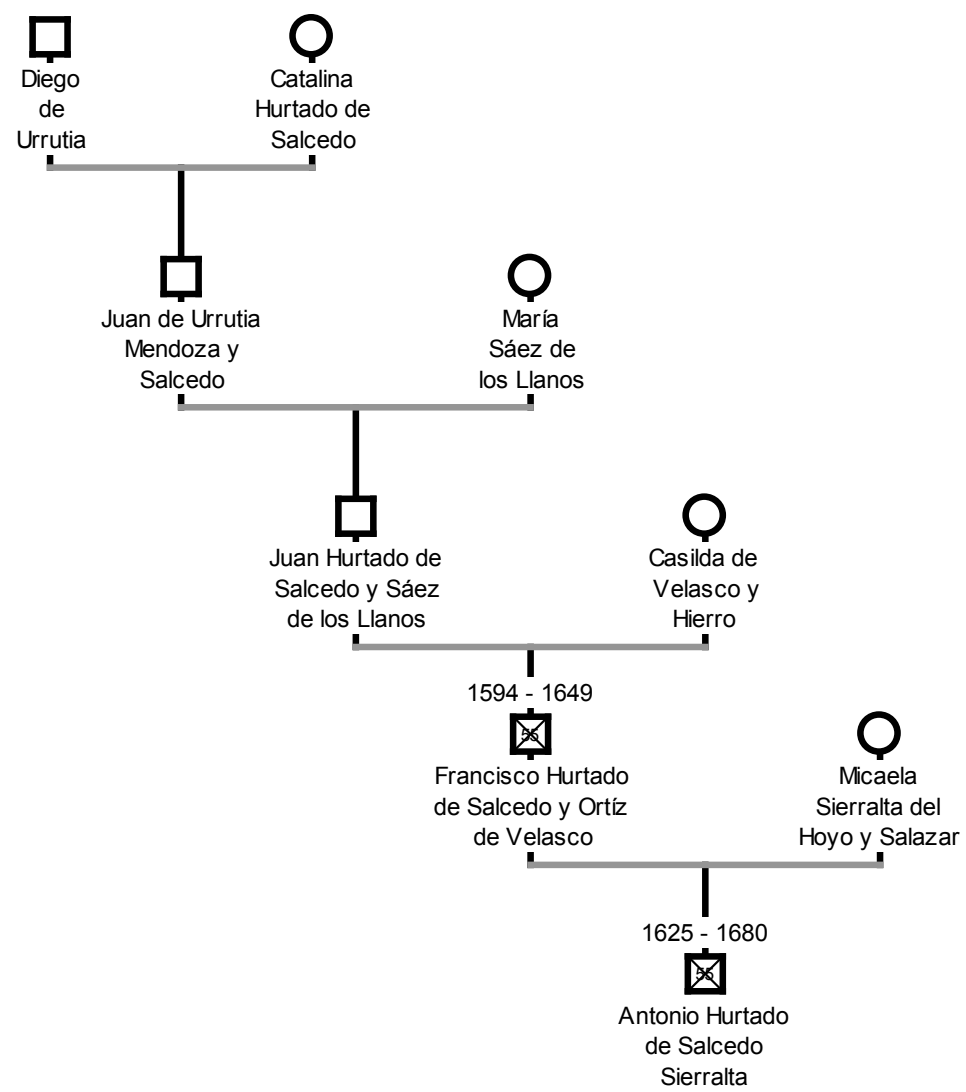

Fuente: elaboración propia utilizando los datos de la nota al pie número 5.

El número de los recuadros hace referencia a la edad alcanzada por los titulares.

Fue entonces cuando se produjo la elevación del señorío de Legarda a marquesado por Real Despacho de 30 de noviembre de 1664, y cuando se concedió el nuevo título a Antonio Hurtado de Salcedo y Mendoza 5 (1625-1680), señor de Legarda y Mendoza, XIII señor de Salcedo y La Jara, y señor de la Casa de Urría. Este personaje, que había nacido en Valmaseda el 19 de mayo de 1625, ya había destacado por su servicio al rey Felipe IV en las guerras contra Francia y en la recuperación de Nápoles durante el levantamiento de Masaniello del año 16476 , lo que probablemente facilitó su nombramiento como caballero de la Orden de Santiago ese mismo año.

${ }^{5}$ También aparece nombrado como Antonio Hurtado de Salcedo Sierralta.

${ }^{6}$ Recogido por el presbítero malagueño A. RAMOS, Aparato para la correción y adición de la obra que publicó en 1769 el Dr. don José Berní y Catalá, Abogado de los Reales Consejos, con el título: Creación, antigüedad y privilegios de los Títulos de Castilla, Málaga, 1777, p. 125, § 303. Recurso electrónico: http://books.google.es/books?id=ls0WAAAAQAAJ\&pg=PA125\&lpg= PA125\&dq $=$ marquesa $+d e+$ legarda\&source $=$ bl\&ots $=i C 1$ KRBYTA3\&sig $=$ USK1rE8NIPsVEpDXI Q4eo09m9LU\&hl=es\&sa $=$ X\&ei=82k-U-iyHZDT7AalrIGABg\&ved=0CDMQ6AEwATgK\#v=one page $\& q=$ marquesa $\% 20 \mathrm{de} \% 20$ legarda $\& \mathrm{f}=$ false 


\section{EFrÉn de la PeÑa Barroso y José Francisco Guelfi CAMPos \\ El Fondo DEL MARQueSAdo DE LEGARDA EN El ARChivo HistóRICO DE LA Nobleza (Toledo)}

A su regreso de Italia, y hasta 1664, Antonio Hurtado de Salcedo fijó su residencia en Sevilla. Allí conoció al pintor Bartolomé Esteban Murillo, circunstancia que aprovechó para encargarle un retrato como cazador que ha sido considerado como uno de los retratos más espectaculares de la pintura española del siglo XVII ${ }^{7}$ :

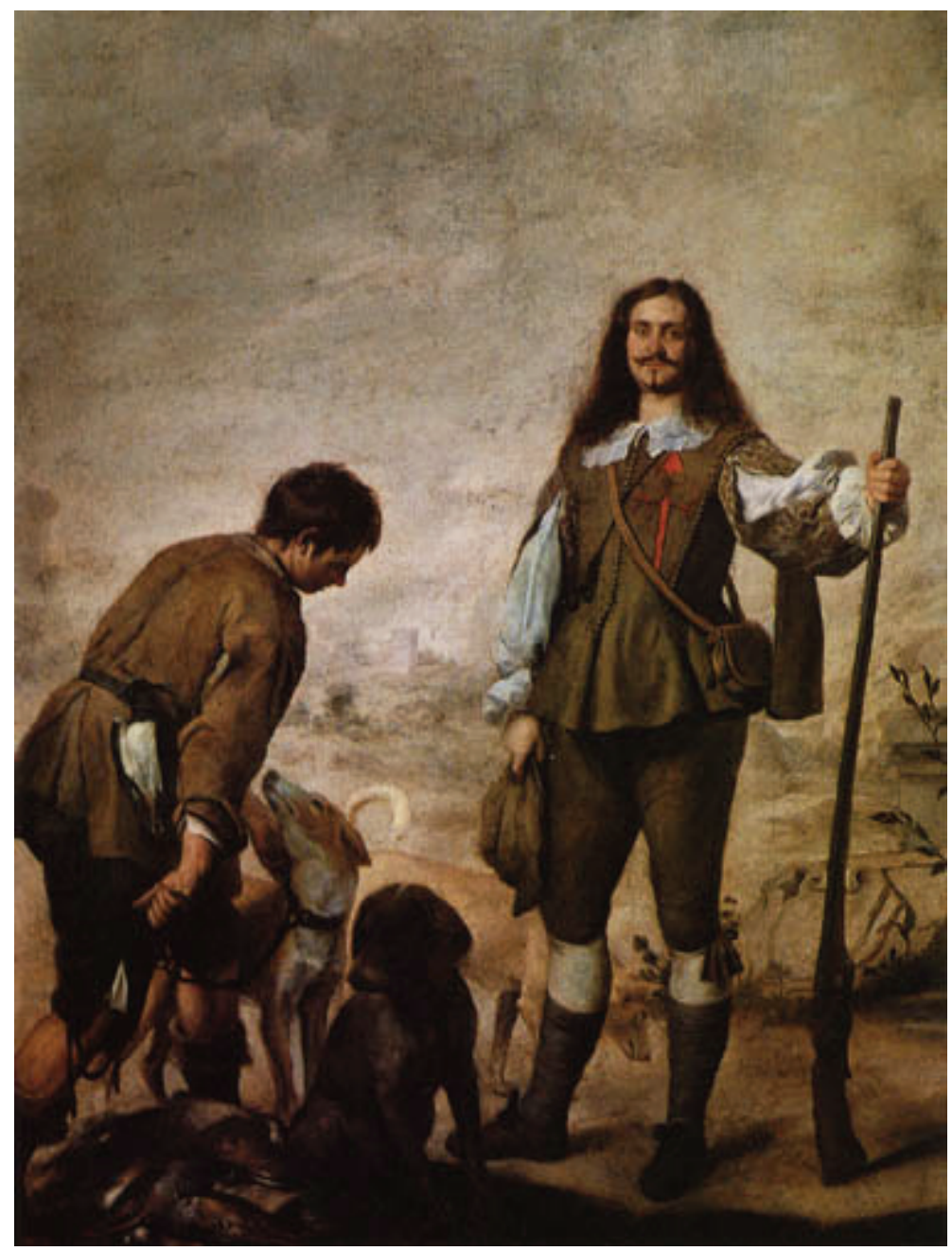

Bartolomé Esteban Murillo: "El cazador”.

Una vez que Antonio Hurtado de Salcedo fue elevado a marqués de Legarda en 1664, fue también nombrado secretario del rey Felipe IV, por lo que es de suponer que se trasladase a Madrid para estar cerca del soberano y de su Corte.

${ }^{7}$ Sobre este cuadro, conocido como "el Cazador", y los que acompañaban a la colección de los marqueses, véase el trabajo de S. SILVA y VERÁSTEGUI, "Aportación al estudio de las colecciones privadas vitorianas", en Ars bilduma: Revista del Departamento de Historia del Arte y Música de la Universidad del País Vasco 1, (2011), pp. 55-64. Recurso electrónico: http://www. ehu.es/ojs/index.php/ars_bilduma/article/view/938 


\section{EFrÉn de la PeÑa Barroso y José Francisco Guelfi CAMPos \\ El FONDO DEL MARQUESADO DE LEGARDA EN El ARCHIVO HistóRICO DE LA NoBLEZA (Toledo)}

Las fuentes recogen que el marqués contrajo matrimonio en 1665 con María Francisca de Coterillo Ortega Calderón ${ }^{8}$. Sin embargo, esta fecha se nos antoja demasiado tardía, habida cuenta de que sus hijos habían nacido antes de la misma. De una forma o de otra, la marquesa de Legarda también se hizo retratar por Murillo entre 1662 y 1664. Los especialistas en arte han atribuido la pintura al taller del pintor sevillano, aunque se desconoce el grado de participación del artista en el cuadro:

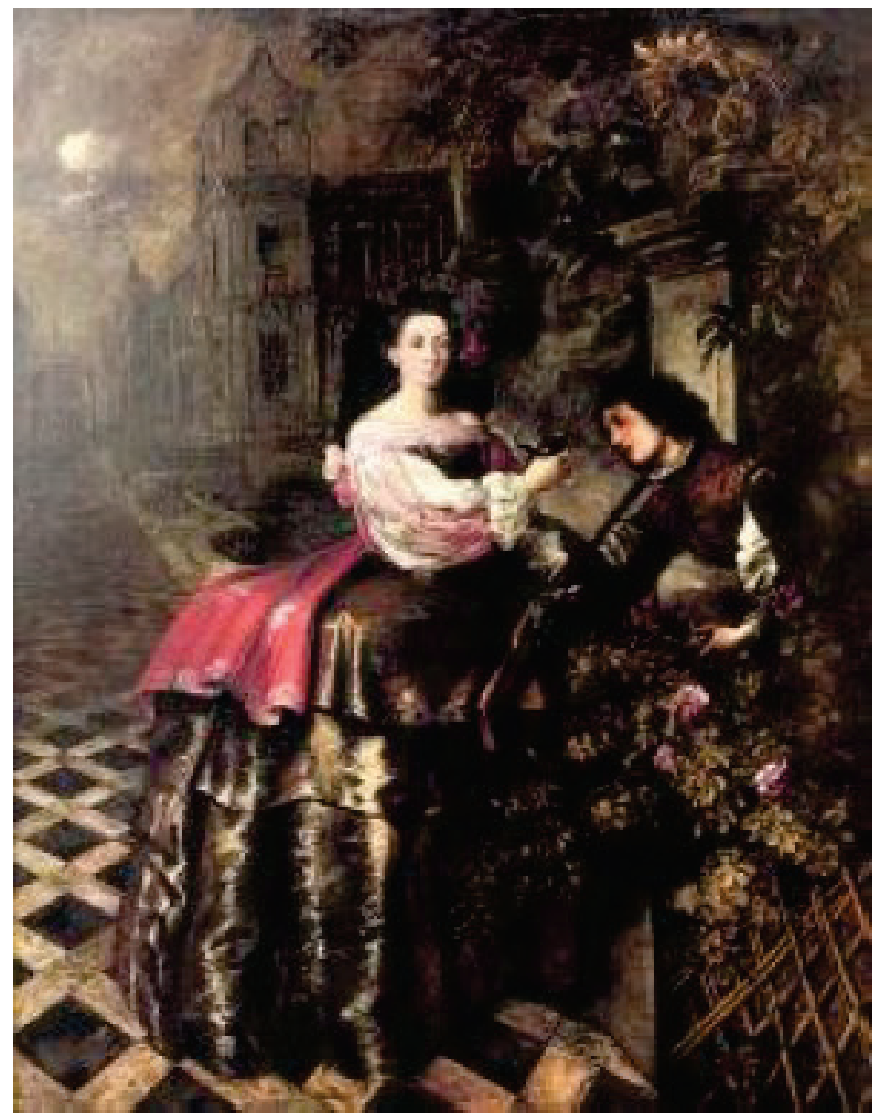

Bartolomé Esteban Murillo: "Retrato de doña María Francisca Coterillo y Ortega, $1{ }^{a}$ marquesa de Legarda, en traje de caza".

Los marqueses tuvieron cuatro hijos, pero quien continuó la linea del marquesado fue la primogénita Bernarda Hurtado de Salcedo Mendoza (1660-1689), II marquesa de Legarda desde la muerte de su padre. Su consorte, Luis de Peralta Cárdenas, con quien casó en 1680, fue además II vizconde de Ambite, Caballero de la Orden de Alcántara y miembro del Consejo de Hacienda. También fue Veedor General de Flandes y corregidor de Antequera.

\footnotetext{
${ }^{8}$ También aparece nombrada como María Francisca de Coterillo Arga.
} 


\section{EFrÉn de la PeÑa Barroso y José Francisco Guelfi CAMPoS \\ El FONDO DEl MARQueSAdo DE LEGARDA EN El ARCHIVo HistóRICO DE LA NobleZA (Toledo)}

La documentación presenta ciertas incoherencias en relación a este último personaje. En algunos documentos aparece nombrado como Alonso de Peralta Cárdenas y también como Alonso Cárdenas Pacheco ${ }^{9}$, por lo que pueden lanzarse algunas hipótesis al respecto: en primer lugar, y teniendo en cuenta la ausencia de estándares para la composición de nombres en esta época, es posible que Luis y Alonso fueran la misma persona y que en los documentos no se utilizase su nombre completo y se alternase entre ambos. También podría considerarse la posibilidad de que Luis de Peralta Cárdenas y Alonso Cárdenas fuesen hermanos y que uno ostentase el título tras la muerte del otro. Pero aún existe una tercera suposición, y es que Bernarda Hurtado de Salcedo Mendoza casase en dos ocasiones. Según el tenor de uno de los documentos, se sabe que en 1679 Alonso Cárdenas Pacheco ya había fallecido ${ }^{10}$. Sin embargo, el primogénito de la marquesa (Juan José Peralta Cárdenas) nació ocho años más tarde, en 1687, y dos años antes de la muerte de su madre. De este modo, es muy probable que Luis de Peralta Cárdenas fuese el segundo marido de Bernarda Hurtado de Salcedo, con quien ella casó precisamente para tener un hijo en quien poder transmitir el título nobiliario. De hecho, a partir de Alonso Cárdenas todo apunta a que los títulos de vizconde de Ambite y de marqués de Legarda se unieron en la misma persona.

Como acabamos de decir, el 12 de junio de 1687 nació Juan José Peralta Cárdenas (1687-1754), también nombrado en los documentos como Juan José Peralta Salcedo o Juan José de Peralta Cárdenas Salcedo Guzmán, III marqués de Legarda. Poco se sabe de su vida, excepto que contrajo matrimonio el 10 de diciembre de 1718 con Teresa Vivanco Olaso (1701-1773), hija de José de Vivanco Angulo y de Antonia de Olaso Angulo.

La primogénita de ambos fue Antonia Javiera de Peralta Cárdenas y Salcedo $^{11}$ (1719-1803), IV marquesa de Legarda ${ }^{12}$. Contrajo matrimonio en 1736 con José Manuel Esquivel Ribas y Verástegui. La marquesa y su esposo también ostentaron los títulos de vizcondes de Villahermosa, V vizcondes de Ambite, y señores de Valtierra, Villanueva de Mingorría, San Esteban de los Patos y de la Torre Fuerte de Salcedo. En el año 1745 tuvieron su primer hijo, llamado Ignacio de Esquivel, que sucedió en el titulo nobiliario.

\footnotetext{
${ }^{9}$ Los documentos aún presentan otras dos formas del nombre: Alonso Pacheco Cárdenas y Alonso Peralta Cárdenas Guzmán.

${ }^{10}$ Archivo Histórico de la Nobleza (en adelante AHNob), LEGARDA, C.3, D.53.

11 También aparece nombrada como Antonia Javiera de Peralta Cárdenas Salcedo y como Antonia Peralta Vivanco.

${ }^{12}$ Antonia Javiera accedió al título tres años antes de la muerte de su padre, esto es, en el año 1751. AHNob, LEGARDA, C.2, D.68.
} 


\section{EFrén de la PeÑa Barroso y José Francisco Guelfi Campos \\ El FONDO DEL MARQUESADO DE LEGARDA EN EL ARCHIVo HistóRICO DE LA NobleZA (Toledo)}

Ignacio de Esquivel y Peralta (1745-1814), V marqués de Legarda, accedió al titulo en 1803 y lo ejerció hasta la fecha de su muerte. En 1775 había casado con Manuela Isidra de Navarrete Lisón Ladrón de Guevara y Ponferrada ${ }^{13}$, con quien tuvo a Álvaro José de Esquivel Navarrete, que había de ser el sucesor natural al título. Sin embargo, Álvaro José murió en el año 1800 sin haber accedido al marquesado. Tras la muerte de Ignacio de Esquivel y Peralta el titulo fue transmitido a su nieto Antonio María de Esquivel.

Este Antonio María de Esquivel Verástegui ${ }^{14}$ (1801-1860), VI marqués de Legarda y vizconde de Villahermosa de Ambite, era hijo post-mortem de Álvaro José de Esquivel y María de los Dolores Sanz de Navarrete, y nieto de Ignacio de Esquivel y Peralta y de Manuela de Navarrete. Como acabamos de decir, Antonio María de Esquivel accedió al marquesado en 1814, tras la muerte de su abuelo, ya que su padre (el sucesor natural) había fallecido en 1800. Contrajo matrimonio en 1821 con María Anselma Ruiz de Pazuengos ${ }^{15}$, con quien tuvo varios hijos. Su hijo Julián Esquivel, senador por la provincia de Álava en el año $1872^{16}$, fue quien heredó el título nobiliario. Otro de sus hijos, José Esquivel, ingresó en 1856 en el sanatorio mental de Santa Isabel, en Leganés (Madrid), "por padecer simplicidad de espíritu con alucinaciones", acompañado además de un criado de la Casa que había de cuidar de él ${ }^{17}$. Con este sinsabor, Antonio María de Esquivel murió en Madrid en 1860.

Heredó el título su hijo y senador Julian Esquivel y Ruiz de Pazuengos (1822-1881), VII marqués de Legarda desde el año 1861, quien contrajo matrimonio diez años después con Luisa Martínez de Pinillos y Martínez de Maturana.

\footnotetext{
${ }^{13}$ Algunas notas sobre estos personajes en A. CHAPARRO SÁINZ, "La génesis social de una familia ilustrada vasca en el siglo XVIII", en Cuadernos de Historia Moderna 37, (2012), pp. 191-193. Recurso electrónico: http://revistas.ucm.es/index.php/CHMO/article/view/39235

${ }^{14}$ También aparece nombrado como Antonio de Esquivel Sanz de Navarrete; Antonio María de Esquivel; y Antonio María de Esquivel, Verástegui, Rivas, Peralta, Salcedo Portocarrero, Hurtado de Mendoza.

${ }^{15}$ El contrato matrimonial y los esponsales están en el Archivo Histórico-Provincial de Álava, ESC, 31812. Fechado el 12 de marzo de 1821.

${ }^{16}$ Información extraída de su partida de bautismo contenida en su expediente personal de senador y disponible en: http:/www.senado.es/web/conocersenado/senadohistoria/senado18341923/ senadores/fichasenador/index.html?id1=3236

${ }^{17}$ Véase el interesante artículo de E. MOLLEJO APARICIO, "La presencia de criados particulares en la Casa de Dementes de Santa Isabel”, en Revista de la Asociación Española de Neuropsiquiatría, vol 33, no 118, (2013), pp. 425-441. Recurso electrónico: http:/www.revistaaen.es/ index.php/aen/article/view/16616
} 


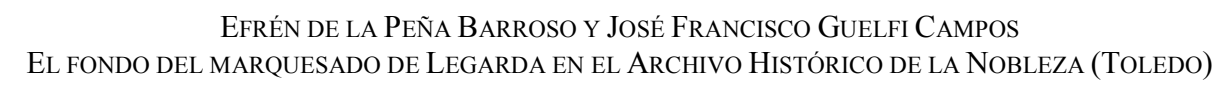

Sin embargo, la muerte sin descendencia del senador provocó que el título de Legarda recayese en su hermano José ${ }^{18}$.

Todo apunta a que este José (ca.1835-1895), que se convirtió en el VIII marqués de Legarda, era el mismo que había ingresado en el sanatorio de Santa Isabel, y también murió sin descendencia.

El marquesado recayó entonces en Antonio Fernández de Navarrete y Hurtado de Mendoza (1859-1936), IX marqués de Legarda, que provenía de la línea de Antonia Esquivel y Navarrete (1778-1849), otra de las hijas de Ignacio de Esquivel Peralta y de Manuela Isidra de Navarrete Lisón, $\mathrm{V}$ marqueses de Legarda. Antonio Fernández de Navarrete casó con Micaela Rada Mancebo, con quien tuvo dos varones y dos hembras.

El primogénito y heredero fue Francisco de Paula Fernández de Navarrete y Rada (1889-1960), X marqués de Legarda.

Actualmente, y desde el año 1962, el título lo posee Francisco Fernández de Navarrete y López Montenegro, XI marqués de Legarda, que está casado con Isabel Garaizábal y Verástegui ${ }^{19}$.

\section{ORGANIZACIÓN DEL ARCHIVO DURANTE EL ANTIGUO RÉGIMEN.}

Una vez vista de forma somera la historia genealógica del título nobiliario de Legarda, analizaremos la organización de los documentos de su archivo.

\subsection{Caracteres externos.}

Lo primero que ha de sorprender al investigador en su acercamiento inicial al fondo de los marqueses de Legarda conservado en el Archivo Histórico de la Nobleza es su pequeña extensión. Toda la documentación se conserva en tan sólo cuatro unidades de instalación, un rasgo llamativo por cuanto la existencia de este título nobiliario y de sus antepasados que gozaron de una condición pre-nobiliaria se extiende durante un período temporal de más de cinco siglos.

\footnotetext{
18 Véase la entrada $\mathrm{n}^{\circ}$ 44, dedicada a Julián Esquivel Ruiz de Pazuengos, del Diccionario biográfico de los Diputados Generales, burócratas y patricios de Bizkaia (1800-1876), dirigido por J. AGUIRREAZKUENAGA, coordinado y editado por J. AGUIRREAZKUENAGA y M. URQUIJO, Bilbao, Juntas Generales de Bizkaia, 1995, pp. 205-206. Recurso electrónico: http:// www.ehu.es/ituna/pdf/DiccionarioDiputadosGenerales.pdf

${ }^{19}$ Véase el Elenco de Grandezas y Títulos Nobiliarios españoles, Madrid, Ediciones de la Revista Hidalguía, 2013, p. 519, § Legarda, Marqués de.
} 
Las fechas extremas de la documentación son los años 1558 y 1838. Cada unidad de instalación presenta un orden cronológico individual, esto es, que la caja 1 tiene unas fechas extremas de 1558 a 1838; la caja 2 de 1560 a 1800; la caja 3 de 1602 a 1828; y la caja 4 de 1645 a 1834. Referenciadas estas fechas, y sobre todo después de analizar las anotaciones puestas por los distintos archiveros de la casa sobre los documentos, que estudiaremos a continuación, se llega a la conclusión de que el fondo Legarda conservado en Toledo está incompleto, característica que además va a condicionar el estudio de la institución y de su archivo.

El interior de cada caja contiene un número indeterminado de documentos de papel en folio formando pliegos, que las más de las veces están encuadernados con un cosido en su lado izquierdo. Tampoco faltan documentos escritos en medio pliego e incluso en cuartillas. Sin embargo, no existe ningún documento en pergamino, y ni siquiera los documentos encuadernados presentan cubiertas o portadas en este material. La lengua de todos los documentos del fondo es el español, y los tipos de letra utilizados son humanísticos y procesales. La conservación general de la documentación es buena.

\subsection{Organización del archivo.}

Una vez repasadas las características externas de la documentación examinaremos el rasgo más característico de la misma: las anotaciones que realizó en los documentos el encargado del fondo en la segunda mitad del siglo XVIII. Con el análisis pormenorizado de todas ellas intentaremos reproducir la organización del archivo durante el tiempo en que estuvo custodiado por sus titulares.

En este sentido, huelga decir que el fondo Legarda estuvo bien organizado donde quiera que se conservase en origen. Sus encargados organizaron toda la documentación en una suerte de cajones, tal y como se desprende de las anotaciones de las portadas de los documentos. Dentro de esos cajones, la documentación se disponía en legajos y, a su vez, dentro de éstos, en cuadernos. Los cajones se ordenaron siguiendo las letras del abecedario, desde la letra A en adelante. Los legajos recibieron un número ordinal corrido desde el 1 en adelante, tal y como sucedió con los cuadernos que contenían.

Uno de los motivos por los que puede asegurarse que el fondo Legarda está incompleto es que los cajones de los cuales tenemos referencia son los correspondientes a las letras A, C, F, Y (que debe entenderse como I) y J. Del resto de letras no se conserva documentación alguna. Pero hay más. En cada uno de esos cajones había varios legajos, aunque ni siquiera nos han llegado legajos completos dentro 
de cada cajón. Por ejemplo, del cajón A tan sólo tenemos un único documento perteneciente al legajo 16, por lo que se deduce que al menos faltan los 15 legajos anteriores $^{20}$. O también el cajón $\mathrm{F}$, cuyos documentos se encontraban en 11 legajos según un inventario conservado ${ }^{21}$, pero de los que sólo tenemos constancia física de los legajos $1,6,7,8,9,10$ y 11.

\subsection{Descripción.}

La existencia de estas anotaciones hace pensar que los encargados del archivo tenían perfecta conciencia de la importancia de su correcta organización y de su conservación. Además, la estructuración en cajones, legajos y cuadernos puede entenderse como un incipiente método de signaturación de la documentación que ayudara a la hora de recuperar la información contenida en determinados documentos. Los inventarios proporcionaban los datos necesarios para la recuperación física de los documentos, y seguramente se guardase un ejemplar en el despacho del encargado del archivo y otro en el propio cajón, separado de las agrupaciones documentales del mismo, como ocurría en otros archivos coetáneos.

Como acabamos de mencionar, sólo se ha conservado el inventario correspondiente al cajón F. La portada de este inventario dice lo siguiente ${ }^{22}$ :

\section{Caxón $\mathrm{F}$}

Apellido de Gauna:

Imbentario de papeles de el apellido Gauna que se hallan en el Caxón F.

La siguiente página del inventario es una especie de índice ordenado por las primeras letras del abecedario en la que cada una se corresponde con una agrupación temática totalmente facticia cuyos tipos documentales comenzaban por la misma letra y que además se vinculaban a un legajo concreto, tal y como ocurría en algunos archivos municipales del mismo período temporal ${ }^{23}$. Así, el inventario sigue:

Breve ynstrucción, y método fácil, para hallar qualquiera ynstrumento en el archivo de la casa de Esquibel, correspondientes al apellido de Gauna, en el Caxón F, valiéndose para el efecto del Ymbentario formado, según el orden alphabético que se seguirá después de esta nota:

${ }^{20}$ AHNob, LEGARDA, C.4, D.14.

${ }^{21}$ AHNob, LEGARDA, C.1, D.11.

${ }^{22}$ AHNob, LEGARDA, C.1, D.11. Lo seguiremos para realizar todo este apartado.

${ }^{23}$ Véanse los ejemplos recogidos por M. GARCÍA RUIPÉREZ y M. C. FERNÁNDEZ HIDALGO, Los Archivos Municipales en España durante el Antiguo Régimen, Cuenca, 1999, pp. 185-239. 
Ajustes, Arrendamientos, en el legaxo $1^{\circ}$.

Censos, Cesiones, Cartas de pago, Comutaciones, Combenios, en el legajo $2^{\circ}$.

Donaciones, Daciones, en el legajo $3^{\circ}$.

Escritura de donación de Francisco de Gauna, por testimonio de Martín Ybañez, en el legaxo $4^{\circ}$.

Fundación del anibersario, en el legajo $5^{\circ}$.

Ymbentarios e Ynformación, en el legajo $6^{\circ}$.

Posesiones y certificación de un juro, ly reintegro de fincas/, en el legaxo $7^{\circ}$.

Quentas de los bienes que donó Francisco de Gauna, en el legajo $8^{\circ}$.

Requisitoria despachada para la tasación de los bienes de la villa de Fonzea, pertenecientes a la donación de Francisco de Gauna, ly Reales Provisiones/, en el legaxo 9.

Testamentos y cobdicilos, en el legajo 10 .

Venta y permutas de casas y heredades en el legaxo 11.

En la siguiente tabla de equivalencias puede compararse el número de cuadernos que originalmente formaban el cajón $\mathrm{F}$ con los conservados en la actualidad:

Documentación del cajón $F$

\begin{tabular}{|c|c|c|}
\hline Número de legajo & Cuadernos que contenía & Cuadernos conservados \\
\hline Leg. 1 & 7 cuadernos & Números 2 y 4 \\
\hline Leg. 2 & 9 cuadernos & Ninguno \\
\hline Leg. 3 & 3 cuadernos & Ninguno \\
\hline Leg. 4 & 3 cuadernos & Ninguno \\
\hline Leg. 5 & 1 cuaderno & Ninguno \\
\hline Leg. 6 & 7 cuadernos & Números $4,5,6$ y 7 \\
\hline Leg. 7 & 4 cuadernos & Números 2 y 3 \\
\hline Leg. 8 & 5 cuadernos & Números $1,2,3$ y 4 \\
\hline Leg. 9 & 3 cuadernos & Número 1 \\
\hline Leg. 10 & 11 cuadernos & Número 7 \\
\hline Leg. 11 & 32 cuadernos & Números 20 y 29 \\
\hline \multicolumn{2}{|c|}{ Totales: } \\
\hline 11 legajos & 85 cuadernos & 16 cuadernos conservados \\
\hline
\end{tabular}

Después, y separados por legajos, se incluía una cuidada descripción de los cuadernos contenidos en cada uno de ellos siguiendo un orden cronológico. Esta descripción comenzaba con el número de cuaderno en el margen izquierdo formando una columna. Seguía la tipología documental, la tradición documental si el documento no era el original, las partes actuantes, el asunto y la fecha, estructura que de nuevo coincidía con la seguida en los archivos municipales de la época. Un 


\section{EFrÉn de la Peña Barroso y José Francisco Guelfi Campos \\ El FONDO DEl MARQueSAdo DE LEGARDA EN El ARCHIVo HistóRICO DE LA NobleZA (Toledo)}

buen ejemplo es el legajo 10, cuyas primeras entradas nos informan sobre dos documentos del siglo XV que no se han conservado:

Legaxo 10

Quaderno $1^{\mathrm{o}}$ : Testamento que otorgó doña María Martínez de Yzarza, muger que fue de Sancho Pérez de Gauna, en 16 de junio de 1451, por testimonio de Francisco Ybañez de Marquina, que se halla concordado y signado de Francisco de Salbatierra, escribano que fue del número de esta ciudad de Vitoria.

[Cuaderno] 2: Testamento otorgado por Sancho Pérez de Gauna, vecino que fue de esta ciudad, por testimonio de Pedro Sánchez de Aramayo, y se halla concordado por Martín de Bermeo, escribano, en 12 de enero de 1463.

El número de cuadernos de cada legajo era variable y dependía de los documentos que contuviese. El legajo 8, por ejemplo, que se conserva casi en su totalidad, quizá no tuviese más de 100 folios de extensión. Y seguramente el legajo 5 tampoco fuese muy voluminoso, aunque tal vez la singularidad de su único cuaderno aconsejase archivarlo de manera independiente ${ }^{24}$.

Pero aún hay más. Gracias a las anotaciones incluidas en las descripciones de ese mismo inventario podemos reconstruir la estructura de otros cajones. Una nota curiosa es que todas estas referencias hacen relación a su conservación en cajones anteriores al F, con lo que parece que la documentación se colocaba en los cajones siguiendo su orden de recepción o tramitación. Distinto era, lo hemos visto, la organización de cada cajón, que efectivamente seguía un patrón alfabético ordenado según las tipologías documentales.

Llegados a este punto, tan sólo nos quedaría hablar de la fecha de composición del inventario del cajón F. Siguiendo las fechas de los documentos inventariados y el tipo de escritura, el inventario contiene entradas seriadas hasta el año 1759. Además, el inventario presenta algunas entradas en letra claramente distinta y posterior fechadas entre 1792 y 1844 . De esto se resume que el inventario original debió de confeccionarse entre 1759 y 1792 , y que en torno al año 1844 se incluyeron algunas adiciones.

Como último dato destacable en materia descriptiva puede apuntarse que también se conservan documentos con notas en las que se recogen descripciones

${ }^{24}$ Esta es la descripción recogida en el inventario: "Fundación de un anibersario en el altar de Santa Susana, del combento de San Francisco de esta ciudad de Vitoria, hecha por Sancho Pérez de Gauna y doña María Pérez de Yzarza, su muger, vecinos que fueron de esta referida ciudad, de tres misas en los lunes de las Pasquas de cada año, para lo qual atributaron una huerta que tenían junto al camino de la Zumaquera en 4 de septiembre de 1452 por testimonio de Fernán Ruiz”. En AHNob, LEGARDA, C.1, D.11. 


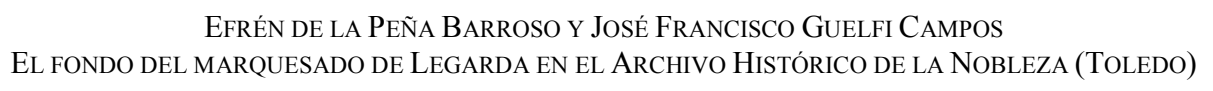

de otros documentos y sus relaciones con otros conservados en diferentes cajones, con expresión de sus correspondientes signaturas ${ }^{25}$.

\subsection{Conservación.}

Atendiendo a la información contenida en estos inventarios podemos extraer algunos datos relativos a la forma de conservación de la documentación de la casa de Legarda. Por lo pronto, parece que en sus orígenes la documentación del marquesado se encontraba parcialmente dispersa en el propio hogar.

Esto se desprende del inventario de bienes realizado cuando murió Ana de Ribas en torno al año 1615. De ella se dice que tenía, entre otras cosas, un escritorio con varios cajones en el entresuelo de sus casas de la ciudad de Vitoria. En los cajones se conservaban documentos y objetos de lo más diverso. Por ejemplo, en un cajón "estava en una caja de oja de lata la carta executoria de ydalguía en pergamino, y otras deligenzias hechas en razón della" 26.

Y junto a la carta ejecutoria había "una probança hecha por el fiscal en raçón del dicho pleyto de ydalguía, y otros papeles biejos que no son de ymportanzia ninguna".

En otros cajones se conservaban más documentos como inventarios y cartas de pago. Así, en uno se guardaba "el ynventario de los bienes de Pedro de Gauna"; algunas "cartas de pago del cumplimiento de su alma y la escriptura de anibersario de la Capilla de la Cruz"; y "un trojelejo de cartas de pago".

En otro legajo del escritorio estaban "las cartas de pago de lo que ha dado doña Ana de Rivas a Pedro de Gauna, su hijo, y otras cossas". Y junto a eso había "seis escripturas de çenso en un trojel" ${ }^{27}$ cuyas cantidades consta por ellas"; "unos papeles biejos de poca ymportanzia".

Y otro contenía "un papel de corchetes"; "unos papeles de el liçençiado Guevara, fiscal de su magestad, que no son de ynportanzia"; y "un libro de quentas de Pedro Pérez de Gauna y otros papeles de poca ymportançia".

En un cajón de ese escritorio había "muchas cartas de Pedro de Gauna para su madre, $y$ de otras personas; y papeles de poca ynportançia".

Y en otro cajón,

${ }^{25}$ AHNob, LEGARDA, C.1, D.28. Este tipo de información demuestra, entre otras cosas, la importancia de los datos contenidos en los inventarios a la hora de recuperar datos históricos cuya documentación original no se ha conservado.

${ }^{26}$ AHNob, LEGARDA, C.1, D.14. Seguiremos el inventario en las posteriores entradas.

${ }^{27}$ Trojel o trojelejo eran sinónimos de la palabra "fardo". 


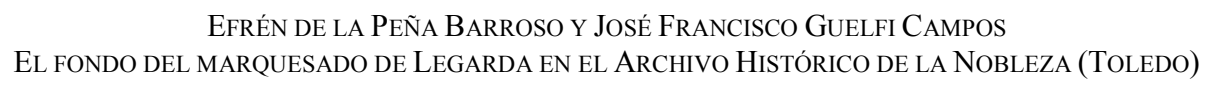

que es el que está devajo del dicho, está en él un libro cubierto de pergamino de letra y mano de doña Ana de Rivas, a donde tiene ymventariada toda la plata y oro y tapiçería, camas y alombras que tiene y deja. Y en él otras quentas con terçeras personas de menudençias, a las quales nos referimos. Y ansímismo está junto con el dicho quaderno otro quaderno sin cubierta ninguna, a donde tiene otras quentas con terçeras personas de letra y mano de la dicha doña Ana de Rivas. Y cuentas con renteros y sus criadas.

Si seguimos recorriendo el hogar a través de las anotaciones de este inventario encontraremos otra entrada que recoge que había una mesa "en el dicho entresuelo con dos tiradores, que se halló en el uno dellos papeles viejos de cartas". En otro lugar de la casa había "un escriptorio pequeño de tarazea no fino" y "otro escriptorio de aciprés (sic)", ambos con numerosos cajones que, sin embargo, no contenían documentos, aunque en uno de ellos sí que había "unos libros de poca ynportanzia". Por último, sabemos que en otra estancia del hogar había "una arca pequeña de madera, toda ella de papeles".

Por lo tanto, la dispersión de la documentación en la propia casa, aunque concentrada en varios lugares precisos, demuestra que el archivo físico no era entendido en esta fecha como un habitáculo del hogar exclusivo para estos fines. Eso sí, son evidentes algunos criterios de conservación incipientes, como la cajita de hojalata que conservaba uno de los documentos más importantes de la casa o la instalación de la documentación en los escritorios repartidos por el hogar. También debe destacarse el interés de los titulares por conservar tantos "papeles de poca importancia" en lo que, cuanto menos, parece un ejercicio de responsabilidad ante un posible expurgo indiscriminado.

Un siglo después, cuando la casa de Legarda estaba ya perfectamente consolidada como título nobiliario se asistió, o al menos eso parece, a una tímida evolución en los métodos de conservación. Aunque el espacio físico destinado a archivo todavía no exista como tal, parece que el mobiliario específico destinado a conservar documentos se hizo exclusivo para tal fin. Así se desprende de las notas o signaturas escritas sobre los documentos y que hemos analizado en el epígrafe anterior.

Este mueble-archivo debió estar dividido en cajones, un mínimo de 10 si tenemos en cuenta que se documentan cajones de la letra A a la letra J. Esos cajones, como ya hemos apuntado anteriormente, se componían de un número de legajos, y estos a su vez de un número de cuadernos o documentos. Por comparación, un cajón debía ser equivalente, poco más o menos, al volumen físico de una caja de archivo actual. Y, por lo tanto, si existía un número de cajones superior a 10, eso significa que el archivo de los marqueses de Legarda a mediados del siglo 


\section{EFrén de la Peña Barroso y José Francisco Guelfi CAMPos \\ El FONDO DEL MARQUESADO DE LEGARDA EN EL ARCHIVo HistóRICO DE LA NoBleZA (Toledo)}

XVIII debió tener una extensión aproximada de 10 a 15 cajas de archivo, tomando esta afirmación con las máximas reservas.

Si así hubiese sido, todo el archivo podría estar contenido en una alacena o mueble-archivo como el conservado y expuesto en el Archivo Municipal de Toledo. Estos muebles se fabricaban en madera, y estaban cerrados por puertas protegidas por planchas de hierro y varias cerraduras. La parte superior se dividía en cajones, mientras que en la inferior se disponían alacenas con un sistema de apertura independiente. Entre ambas zonas se solía colocar una plancha de madera extraíble con la finalidad de escribir o de consultar los documentos "in situ"28.

De este modo, y resumiendo todo lo anterior, nos encontramos ante un archivo nobiliario fragmentado, en buen estado de conservación y con unas fechas extremas que abarcan casi 300 años pero del que sabemos conservaba documentos anteriores. Muy bien organizado en cajones y legajos durante el siglo XVIII, se ha conservado también un minucioso inventario que evidencia las buenas prácticas archivísticas de la casa. Veamos ahora qué información histórica puede extraerse de la documentación de este fondo.

\section{LOS DOCUMENTOS DEL ARCHIVO Y SU UTILIDAD PARA LA HISTORIA.}

Aunque de reducido tamaño en términos de volumen, el archivo de los marqueses de Legarda abarca un amplio arco cronológico. Con evidentes lagunas, sus documentos cubren un período de cuatro siglos, desde 1558 hasta 1838. Por lo tanto, el archivo se emplaza históricamente en el momento del crecimiento de la burocracia y de la producción escrita que se produjo a partir del siglo $\mathrm{XVI}^{29}$.

El listado de los lugares de expedición de los documentos también es un elemento relevante para visualizar la dispersión territorial de las propiedades de los marqueses de Legarda, pero también las familias ennoblecidas con quienes mantuvieron relación a través de alianzas y matrimonios. Entre los lugares representados en la documentación destaca la villa de Madrid, donde los miembros de la familia tuvieron diversos inmuebles y en la que fueron patronos de obras pías en el Convento de Santa Ana y en el Monasterio de San Bernardo.

\footnotetext{
${ }^{28}$ Algunas notas sobre estos muebles en M. GARCÍA RUIPÉREZ y M. C. FERNÁNDEZ HIDALGO, Los Archivos Municipales..., pp. 125-131.

${ }^{29}$ A. HEREDIA HERRERA, Archivística general: teoría y práctica, Sevilla, Servicio de Publicaciones de la Diputación de Sevilla, 1993 (6ª ed.), p. 107.
} 


\section{EFrén de la Peña Barroso y José Francisco Guelfi CAMPos \\ El FONDO DEl MARQueSAdo DE LEGARDA EN El ARCHIVo HistóRICO DE LA NobleZA (Toledo)}

Poco más de ocho docenas de documentos hacen referencia a las heredades y cultivos en Ambite, villa madrileña de la que fueron señores los marqueses de Legarda, desde su segunda generación, momento en que -según todo indica- se unieron los títulos del vizcondado de Ambite y del marquesado de Legarda. En el archivo familiar también se encuentran documentos referentes a Vitoria (Álava), lugar de nacimiento de Antonio Hurtado de Salcedo, el que fuera primer marqués de Legarda.

Desde el norte hacia el sur de la Península aparecen citados en la documentación los lugares de Uriarte (País Vasco); Foncea (La Rioja); Burgos; Zaragoza; Mingorría (Ávila); Modéjar (Guadalajara); Alcalá de Henares, Arganda del Rey, Campo Real, Leganés, Pezuela de las Torres, Valdilecha, Vallecas y Villar del Olmo (Madrid); Saelices (Cuenca); Almagro (Ciudad Real); Sevilla; Sanlúcar de Barrameda (Cádiz); y Granada. Toledo, ciudad donde actualmente se conserva el archivo, también se menciona en algunos documentos y figura como el lugar de expedición de otros ${ }^{30}$.

La tipología de documentos que nos brinda el fondo en cuestión es muy amplia: escrituras, cartas de poder, autos criminales, memoriales, testimonios, declaraciones, instrucciones, inventarios, cuentas, testamentos, recibos o nombramientos, entre tantos otros, nos permiten constatar la riqueza que representa esta documentación para la investigación histórica (social, política y económica, de las instituciones, etc.) y de otros campos del conocimiento.

Indudablemente este archivo es la fuente básica de información acerca de la historia de la propia familia que lo mantuvo durante tantos años. Poco se sabe del linaje de Legarda, por lo que sus documentos pueden ayudarnos a sistematizar mejor la sucesión de los poseedores del título aunque queden todavía muchos huecos que cubrir. El trabajo con fuentes y bibliografia cruzadas sobre las familias Gauna, Hurtado de Salcedo, Peralta, Esquivel y Fernández de Navarrete, con las cuales se unieron los titulares del marquesado de Legarda mediante alianzas y matrimonios, podrá aportar nuevas informaciones al estudio genealógico de la familia.

La temática de la documentación es igualmente variada, pero hay que destacar los numerosos documentos relativos a la administración de bienes, al ejercicio de la jurisdicción señorial y a la gestión de las obras pías. La nobleza, como grupo inserto en una rígida sociedad estamental, participó activamente del ejercicio del poder de gobierno y de la justicia. Su fuerza y riqueza estaban basadas en el nú-

\footnotetext{
${ }^{30}$ Véanse, por ejemplo, AHNob, LEGARDA, C.2, D.19; C.4, D.23 y C.4, D.68.
} 


\section{EFrÉn de la PeÑa Barroso y José Francisco Guelfi CAmPos \\ El FONDO DEL MARQUESADO DE LEGARDA EN EL ARCHIVO HistóRICO DE LA NobLEZA (TOLEDO)}

mero de posesiones territoriales que acumularon y en los títulos nobiliarios, privilegios y mercedes que habían recibido del monarca y con quien buscaron estrechar sus lazos y mantenerse cerca.

Gran parte de los documentos de los marqueses de Legarda se refieren a la administración de los bienes, muebles e inmuebles, y al ejercicio de la jurisdicción señorial en el territorio de la villa de Ambite, situada en los actuales límites de la provincia de Madrid. Sin embargo, los papeles más antiguos se refieren constantemente a sus propiedades en Vitoria (Álava). Una de las posibilidades que nos ofrece esta documentación es la de reflejar la variedad de especies cultivadas y la extensión territorial de las actividades de explotación forestal realizadas en sus propiedades. Huertas, alamedas, cañamares y olivares son referencias frecuentes en diversos documentos del fondo que nos permiten conocer los engranajes del ejercicio del poder frente a la administración de dichas posesiones a partir de declaraciones, testimonios y autos seguidos tras acciones de cortes desautorizados de vigas de madera ${ }^{31}$ y daños causados a los cultivos ${ }^{32}$.

Aún en el terreno de la administración de bienes, cabe señalar los documentos referentes a censos y a arrendamientos, que tanto abundan en este fondo, representados por cuentas, escrituras y cartas de pago. En su conjunto, estos documentos revelan la extensión y la variedad de las propiedades pertenecientes a los marqueses de Legarda, que no se restringen sólo a las tierras destinadas a la explotación forestal y a la cría de ganado sino que también ilustran testimonios en los que se citan molinos, batanes y varias casas en la villa de Madrid. Además de esto, y siempre que sean analizados junto con fuentes de otras procedencias, algunos documentos del fondo pueden resultar de mucho interés para el estudio de la circulación monetaria, de la fluctuación de valores y precios y de los sistemas de pago $^{33}$. Otros documentos como las relaciones de cuentas, que suelen cubrir períodos más o menos largos de tiempo, pueden ser especialmente interesantes en este sentido ${ }^{34}$

El lugar destacado ocupado por la práctica religiosa en la vida de los miembros de la nobleza se refleja en los diversos documentos referidos a las obras pías. La más antigua de las conservadas en el archivo es la fundada por Francisco de

${ }^{31}$ AHNob, LEGARDA, C.1, D.3; C.2, D.35; y C.2, D.51.

${ }^{32}$ AHNob, LEGARDA, C.1, D.8.

${ }^{33}$ Abundan las fuentes relativas a la gestión de censos, representados por escrituras, reconocimientos, rendiciones, razones, cuentas, recibos y cartas de pago que, en conjunto, suman más de treinta documentos.

${ }^{34}$ AHNob, LEGARDA, C.3, D.50. 


\section{EFrÉn de la PEÑa BARRoso y José Francisco Guelfi CAMPOS \\ El FONDO DEL MARQUESAdo DE LEGARDA EN EL ARCHIVO HistóRICO DE LA NoblezA (Toledo)}

Gauna, en el año 1600, cuyo patronazgo y administración ostentaron posteriormente los marqueses de Legarda ${ }^{35}$.

También abundan los documentos relativos a las cuentas de las obras pías fundadas por los miembros de la familia en diferentes conventos y monasterios. Se constituyeron misas rezadas con motivo de defunciones, así como limosnas, capellanías y dotaciones de jóvenes huérfanas ${ }^{36}$, mantenidas por los miembros de la familia de los marqueses de Legarda a lo largo de varias generaciones.

Además, ciertos documentos del fondo nos ofrecen testimonios interesantes para el estudio de la historia de las instituciones religiosas en España y su relación con la nobleza. Más allá de las diferentes formas que asumieron las obras pías, la documentación nos ofrece datos sobre la administración de los conventos y monasterios, de los cuales cabe destacar el convento de Santa Ana y el monasterio de San Bernardo, ambos en Madrid. Entre estos documentos se pueden encontrar, por ejemplo, recibos otorgados a favor del procurador del monasterio de San Bernardo por el pago de deudas contraídas por dicho monasterio ${ }^{37}$, además de varios testimonios sobre los pleitos seguidos por esas instituciones ${ }^{38}$ y sobre la gestión de los recursos percibidos ${ }^{39}$.

Al recorrer los más de trescientos documentos presentes en el fondo de los marqueses de Legarda es posible encontrar también fuentes que proporcionan al investigador las huellas de ciertos episodios de la vida cotidiana, como los testimonios acerca de desobediencias y ofensas proferidas por diversos vecinos de la villa de Ambite ${ }^{40}$, o las causas criminales seguidas por delitos como el robo de miel, paja y frutas, así como por fugas de la cárcel ${ }^{41}$.

La variedad de tipos documentales conservada en el fondo tiene especial importancia para los estudios que van más allá del campo de la Historia y que se relacionan con otras áreas del conocimiento. El largo alcance temporal de la documentación permite acercarse a las fórmulas diplomáticas y a las estructuras formales comúnmente empleadas en la producción de documentos y aceptadas, en

${ }^{35}$ AHNob, LEGARDA, C.1, D.22.

${ }^{36}$ Los documentos relativos a las obras pías constituyen parte considerable del contenido del fondo. Así, véanse, por ejemplo: sobre la obra pía fundada por Francisco de Gauna en el año 1600: AHNob, LEGARDA, C1, D1; C.1, D.21-23; y C.2, D.4. Sobre dotaciones de huérfanas: AHNob, LEGARDA, C.1, D.29-42. Sobre misas: AHNob, LEGARDA, C.3, D.61-62; C.3, D.64; y C.3, D.80.

${ }^{37}$ AHNob, LEGARDA, C.3, D.58-60.

${ }^{38}$ AHNob, LEGARDA, C.4, D.12; C.4, D.39; y C.4, D.79.

${ }^{39}$ Véanse, por ejemplo: AHNob, LEGARDA, C.4, D.39-41; C.4, D.62; y C.4, D.65.

${ }^{40}$ AHNob, LEGARDA, C.2, D.53.

${ }^{41}$ AHNob, LEGARDA, C.2,D.40; y C.2, D.21. 


\section{EFrén de la Peña Barroso y José Francisco Guelfi CAMPos \\ El FONDO DEl MARQueSAdo DE LEGARDA EN El ARCHIVo HistóRICO DE LA NobleZA (Toledo)}

sus contextos originarios, para la acreditación de los hechos jurídicamente relevantes $^{42}$. Considerados en serie, estos documentos aportan información para los estudios acerca de la evolución y del desarrollo de la tipología documental a lo largo de los años, materia de especial interés para las investigaciones en el campo de la Diplomática.

$\mathrm{Si}$, por un lado, se presta atención al contenido de los documentos presentes en el fondo, por otro se olvida estudiar ciertos elementos que componen la estructura del archivo. De manera acertada, Angelika Menne-Haritz afirmó que "los archivos no deben ser leídos, sino entendidos" ${ }^{43}$. Así, entender un archivo significa, en buena medida, intentar comprender su propia historia, el recorrido de los documentos desde su creación hasta su destino final: las cajas y estanterías de los Archivos u otras instituciones de memoria, nombradas genéricamente "aparatos culturales", donde pueden pasar a las manos de los investigadores, revestidos de objetivos e intereses radicalmente distintos de los que motivaron su uso por aquellos que los crearon en un tiempo remoto.

La fuerza discursiva de un archivo no reside sólo en el terreno de las palabras escritas en sus documentos, sino también en el nivel de lo que no está dicho. Hay determinados aspectos que sólo el silencio de la documentación es capaz de decir y que constituyen información relevante para los archiveros y para los demás investigadores.

Y ¿qué es lo que no nos dice, textualmente, el archivo de los marqueses de Legarda? Si la relación entre los marqueses de Legarda y los vecinos de las villas donde mantuvieron sus posesiones está bien representada por documentos que, a la vez, fueron testigos relevantes de la gestión del patrimonio mueble e inmueble y de la administración de las obras pías, no se encuentran en el fondo datos relativos a las relaciones mantenidas entre los miembros de la familia en su vida privada o a las sucesiones en el título nobiliario, información que, eso sí, puede leerse entre líneas en ciertos documentos.

Información complementaria sobre los marqueses de Legarda puede encontrarse no en su propio archivo, sino en otros archivos como en el Archivo de la Real Chancillería de Valladolid (sobre todo en la Sala de Vizcaya); el Archivo

\footnotetext{
${ }^{42}$ Según Luciana Duranti, son los hechos jurídicamente relevantes los que motivan la producción de documentos y su preservación en los archivos. En L. DURANTI, Diplomática: usos nuevos para una antigua ciencia, trad., prólogo y presentación de Manuel Vázquez, Carmona, 1996.

43 A. MENNE-HARITZ, "Access: the reformulation of an archival paradigm", en Archival Science, Dordrecht, vol. 1, 2001, p. 61. La traducción es nuestra. Recurso electrónico: http://staffwww.uni-marburg.de/ mennehar/publikationen/access.pdf
} 
Histórico-Provincial de Álava; el Archivo Histórico Nacional e incluso algunas secciones del Archivo General de la Administración. Pero el análisis de estos documentos se alejan del propósito de este trabajo ${ }^{44}$.

Las dimensiones reducidas del archivo, en marcado contraste con la extensión temporal abarcada por sus documentos, son también un indicio más para las consideraciones acerca de su trayectoria en el tiempo y en el espacio hasta la actualidad, sujeta tanto a la evolución histórica de la familia - con sus azares, casos y acasos - como también a una suerte de factores y fuerzas que actuaron en contra de su preservación, los expurgos, las selecciones o incluso el posible abandono realizado por sus anteriores responsables.

La relación entre los archivos y la Historia, como se ha pretendido señalar aquí, abre un largo campo para discusiones que van más allá del uso de los documentos para la investigación histórica, promoviendo el encuentro de aportes de distintas áreas del conocimiento en la práctica y en la teoría. Más que agotar el potencial informativo del archivo de los marqueses de Legarda, nuestra intención ha sido la de motivar a los estudiosos e investigadores a conocer en mayor profundidad los documentos que lo componen, sabiendo que en cualquier caso permitirán otras posibilidades de estudio de más amplio alcance.

${ }^{44}$ Todos ellos pueden verse a través del Portal PARES, la plataforma de archivos dependiente del Ministerio de Educación, Cultura y Deporte, con los términos de búsqueda "marqués de Legarda". Accesible a través del enlace: http://pares.mcu.es/ 